\title{
GERENCIANDO QUALIDADE EM SERVIÇOS DE SAÚDE*
}

\author{
Vera Lúcia Peixoto S. Mendes**
}

\begin{abstract}
RESUMO: Trabalho realizado em hospital geral de alta tecnologia, objetivando identificar na gestão, elementos facilitadores e bloqueadores da qualidade dos serviços oferecidos pela unidade de urgência / emergência e detectar como os profissionais de enfermagem percebem e experienciam os mecanismos de garantia de qualidade propostos pela organização. Define-se a qualidade como uma das conseqüências do estilo gerencial, dentro de um contexto de modernização administrativa. Trata-se de um estudo de caso onde foi empregado o Sistema 4T de Likert como método de pesquisa, além de entrevistas e observações focais. A análise dos dados revelou uma heterogeneidade de percepção quanto ao estilo gerencial e uma de finição de qualidade compativel com aquela que reforça os princípios defendidos pela organização.
\end{abstract}

\begin{abstract}
This study was developed in a general hospital oVf advanced technology with the purpose of identifying in its administration elements that might facilitate or block the quality of the services provided by the urgency/emergency unit and detecting how the nursing professionals notice and experience the mechanisms of Quality warranty proposed by the organization. Quality is defined as a result of managerial style within a context of administrative modernization. It is a case study where, besides social-anthropological techniques, Likert's 4 T System was also used as a complementary method of research. The data analysis has revealed heterogeneity of perception as to the managerial style and a definition of quality compatible with the one that strengthens the principles supported by the organization.
\end{abstract}

\section{INTRODUÇÃO}

Este trabalho é parte de uma pesquisa sobre Gestão da Qualidade, realizada em um hospital geral de greande porte. A busca de qualidade associada à produtividade, tornou-se um objetivo das empresas em mercados competitivos, empresas situadas nos setores secundário e terciário da economia, tanto é que hoje se fala em qualidade de quase tudo, qualidade de produtos, serviços, do ambiente, enfim, qualidade de vida. Contudo, a operacionalidade deste conceito é variável e as empresas situadas no setor terciário possuem especificidades que não lhes permitem utilizar os mesmos métodos de controle de qualidade utilizados na indústria. Sabe-se que desde o início do século já existiam tentativas de aplicar técnicas da gerência industrial em unidades hospitalares, mas, é a partir das décadas de 60 e 70 que efetivamente, verifica-se a incorporação desse tipo de técnica gerencial à saúde, graças ao avanço tecnológico e aumento dos custos da assistência médica.

$\mathrm{Na}$ verdade, a preocupação com a qualidade tem estado presente na história da humanidade, especialmente nas relações de troca e está relacionada ao movimento de autodefesa contra as irracionalidades do mercado na sociedade industrial moderna, de forma que a qualidade se ịmpõe como reativa às exigências do sistema produtivo e não é uma dádiva dos produtores para com os consumidores ${ }^{(1)}$.

$\mathrm{Na}$ indústria, um dos papéis do desenvolvimento tecnológico é baratear os custos de produção e ampliar o mercado consumidor. Em serviços de saúde, o

\footnotetext{
* Trabalho apresentado como tema livre no $45^{\circ}$ Congresso Brasileiro de Enfermagem. Prêmio Edith Magalhães Fraenkel. $2^{\circ}$ lugar. Recife - PE, 28 de novembro a 3 de dezembro de 1993.

** Professora auxiliar do Departamento de Enfermagem Comunitária da Escola de Enfermagem da UFBA. Mestranda em Administração pela Escola de Administração da UFBA
} 
avanço tecnológico não vem sendo acompanhado de uma correspondente ampliação do acesso a essas tecnologias e os custos são elevados. $\mathrm{O}$ trabalho em serviços de saúde possui especificidades que devem ser consideradas, tais como: a dependência de mão de obra (capital variável), ou seja a incorporação de tecnologias, não tem substituído o trabalho vivo e tem criado cada vez mais sub-especializações; a heterogeneidade na produção, o que torna as condutas menos suscetíveis à padronização e conseqüentemente dificulta a medição, o controle e a estandardização sem inconveniências contraproducentes ${ }^{(11)}$. Além de que, certas características do processo produtivo e do mercado também podem ser destacadas: a intangibilidade e perecibilidade do produto, fazendo com que o usuário não possa experimentá-lo antes do consumo, e participe do ambiente onde é produzido; serviços de saúde não possuem valor de troca para quem os consome, mas só valor de uso; a incerteza do momento de adoecer; os preços nem sempre são regulados pelo mercado com base nas leis de demanda e of erta; coexistem dois sistemas paralelos de produção (o assistencial, responsável pela produção terminal e o administrativo, responsável pela produção intermediária), por vezes orientadas por diferentes lógicas; o consumidor, na maioria dos casos, não dispõe de informações sobre qual serviço utilizar; e a impossibilidade de realizar avaliações precisas sobre a qualidade torna imprescindíveis a integridade do profissional, a credibilidade da organização e a confiança do paciente. Em relação ao produto dos serviços de saúde há também diferenciações, dado que não está claramente definido qual é a matéria prima do sistema assistencial de produção (a doença, o doente, ou a doença no doente?). Sabe-se que existe a figura do "portador assintomático" e se não estão bem definidos os "inputs", torna-se difícil programar os "outputs". E depois, estas organizações lidam com pessoas em situações que, muitas vezes, são de vida ou morte!

No debate atual sobre Gestão Empresarial no país, as atenções têm se voltado para a questão da qualidade. mas a idéia de Gestão da Qualidade não tem sido usual nos serviços de saúde. onde vem se configurando a chamada gestão do "apagar incêndios", caracterizada pela excessiva centralização administrativa, pela falta de flexibilidade e agilidade que limitam o acesso, elevam os custos, enfim resulta na falta de qualidade e até mesmo a literatura sobre 0 assunto é escassa ${ }^{(3)}$. Os manuais técnicos do Ministério da Saúde estão voltados para quantificar a qualidade através de indicadores que refletem mais as condições de vida e saúde de uma população (taxa de mortalidade infantil e materna, indicadores de morbidade, etc) e indicadores de produtividade (taxa de ocupação, média de permanência, índice de rotatividade do leito) que propriamente a "qualidade total" dos serviços de saúde $(3,10)$.

No momento em que avança o empresariamento do setor e que cada vez mais a saúde é tida como um bem de consumo individual, embora reconhecida formalmente como um direito de cidadania, faz-se necessário desenvolver estudos que aprofundem o conhecimento sobre as especificidades destes serviços e as possibilidades de gestão que facilitem a resolução de problemas de saúde da população que, face à grave crise econômica, tornam-se cada vez piores.

Apesar das dif erenças existentes entre a produção nos setores secundário e terciário da economia, a indústria tem desenvolvido técnicas de controle de qualidade, que devem ser analisadas quanto à possibilidade de se ajustarem ou não a serviços, considerando-se as particularidades qeu envolvem os serviços de saúde. Não se trata de querer adaptar à adminitração hospitalar as técnicas gerenciais japonesas de produção, o Taylorismo ou o Fordismo, mas de discutir qual o conteúdo mordenizador destas técnicas e reconhecer, a nível do mircro-espaço institucional, as contradições e dificuldades que impedem o desenvolvimento de um modelo gerencial eficaz, adequado às necessidades do setor, que facilite a obtenção da qualidade total. Assim, este trabalho objetiva identificar empiricamente, o quanto os mecanismos de gestão utilizados por um hospital geral de grande porte se aproximam de um sitema gerencial orientado para a obtenção da qualidade total (CQTE), quais os seus limites e perspectivas e como os atores institucionais (grupo de enfermagem) experienciam o controle de quaildade proposto pela organização

\section{Qualidade na Indústria}

Inicialmente na indústria, pensava-se que qualidade significava ausência de defeitos e portanto, era oneroso eliminá-los na linha de produção; a responsabilidade pelo controle de qualidade ficava então com o consumidor final, que era ressarcido caso comprasse um produto defeituoso. Posteriormente, a indústria resolveu fazer ela mesma o controle de qualidade através da técnica de inspeção e Shewart desenvolveu em 1931 o método SQC (Statistical Quality Control), que vem a ser o método de controle estatístico de processo, aperfeiçoado por Deming e introduzido no Japão após a segunda guerra mun- 
dial ${ }^{(5)}$. Os japoneses, saídos derrotados da guerra, precisavam recuperar a sua indústria e passaram a adotar a idéia de Controle de Qualidade não só na fábrica, mas na distribuição, controle de estoque e varejo. Desenvolveram então, juntamente com os americanos Deming e Juran, a técnica "Just in Time" (JIT), ou "apenas no tempo", o que significa que cada empregado é responsável pela checagem do que produz não passando adiante peças ou produtos defeituosos. Isso revolucionou a linha de montagem porque reduziu o desperdício, o retrabalho, os estoques e exigiu a participação do trabalhador como um membro ativo na fábrica. Foi introduzido o Controle de Qualidade no plane jamento porque, o produto para sair perf eito teria que ser pensado perfeito, e é incoporado a esta fase do processo, que o Controle de Qualidade passou a ser uma tarefa gerencial. A gestão da qualidade se fundamenta em uma visão sistêmica das organizações, onde as funções do gerente são: evitar problemas (entenda-se administrar conflitos), dispor de meios para aferir resultados (o que em serviços de saúde nem sempre tem sido possível), investigar fatos com bases em dados, métodos e técnicas, ou seja, desenvolver atividades que implicam em planejar, fazer, checar e agir e que correspondem ao ciclo PDCA (plan, do, control and action) ${ }^{(4)}$.

Em mercados competitivos as empresas precisam, além de produzir com qualidade, aqui definida como "def eito zero", de custos reduzidos e ênfase na satisf ação do consumidor, introduzir inovações (melhorias) para garantirem a sua presença no mercado. Assim, é preciso a padronização, o estabelecimento de rotinas claramente definidas e a liberação da gerência para "pensar as inovações". Para tanto, necessita-se de um modelo de gestão diferenciado dos modelos tradicionais, un modelo que envolve padronização, ou seja, normatização, burocratização e até aí nenhuma modernização, mas um modelo flexível, descentralizado, permeável à participação do empregado e sustentado em mecanismos de motivação baseados no método "ganha-ganha"'(9). Este modelo vem sendo denominado no Brasil de CQTE (Controle de Qualidade por Toda Empresa) e muito se relaciona com o Sitema 4T (Total), experimentado por Likert a partir da década de 50 em empresas norte-americanas.

Se na indústria, onde é marcante a presença de capital intensivo (máquinas, equipamentos), tem-se buscado um modelo de gestão mais perneável à participação dos recursos humanos, quanto mais em serviços, onde predomina a dependência de mão de obra. Como é sabido, no hospital, a enfermagem representa o maior contingente populacional e é a profissão que lá permanece efetivamente 24 horas, além do que, atribui-se ao serviço de enfermagem a responsabilidade por cerca de $30 \%$ dos custos de produção dos serviços hospitalares ${ }^{(8)}$, de forma que ao se estudar a gestão da qualidade em um hospital, a enfermagem é um grupo importante.

\section{Qualidade em Serviços de Saúde}

Não é recente a busca de qualidade pelos serviços em saúde. Em 1910 o relatório Flexner já dava conta desta preocupação, apontando falhas identificadas em hospitais americanos, que pudessem comprometer a vida dos pacientes e a reputação da categoria médica. Em 1913, foi fundado o Colégio Americano de Cirurgiões, estabelecendo padrões para funcionamento dos hospitais e em 1918 foi criada a JCAH (Joint Comission on Acreditation of Hospitals), numa resposta à necessidade de assegurar o cumprimento de parâmetros de Garantia de Qualidade(1). A enfermeira Florence Nightingale, interessou-se por sistematizar as estatísticas hospitalares que subsidiassem as avaliações sobre a assistência prestada nos hospitais ingleses e deu grande contribuição à administração hospitalar ${ }^{(13)}$. Vê-se que hoje, os serviços de saúde possuem critérios que podem ser denominados de Garantia de Qualidade, tais como as Comissões de Controle de Infecção Hospitalar (CCIHs), comissões de ética, de revisão de prontuários e de credenciamento. Porém todo esse processo é marcado por um interesse freqüente dos profissionais de saúde.

\section{Sobre as definições de Qualidade}

O pesquisador americano Avedis Donabedian vem, há mais de duas décadas, desenvolvendo estudos sobre avaliação da qualidade do cuidado médico e é reconhecidamente, um teórico do assunto. Portanto, as definições aqui apresentadas terão este enf oque, considerando-se prioritariamente, o seu trabalho de $1980^{(7)}$.

Nos trabalhos de Donabedian ${ }^{(6,7)}$, encontram-se três definições de Qualidade:

- Definição absolutista - onde o que importa é o equilibrio entre benefícios e riscos, sendo que o profissional define os objetivos da atenção e valoriza benefícios e riscos. Esta definição é condicionada pela natureza do problema de sáude, considerando-se o estado da ciência e tecnologia médica e da "arte" da medicina. É uma definição moralmente neutra e privilegia o saber técnico. Em nossos serviços os profissionais de saúde têm esta 
soberania para privilegiar a natureza do problema de saúde? Rompida a barreira do acesso, é possível que sim.

- Definição individualista - quando o juízo sobre a qualidade considera valores, desejos e expectativas do paciente. Esta definição é a que mais se aproxima da definição usada nos demais setores da economia onde, diz-se que não se deve agregar valor a um produto ou serviço se o usuário não $o$ reconhece como tal. Entretanto, em serviços de saúde, associar esta lógica, ou seja, o custo monetário, aos benefícios, pode trazer para o profissional um problema de ordem moral, pois significa dizer que a condição financeira e até cultural, é fator limitante para o bom cuidado.

- Definição social - é aquela que, além do benefício líquido, prioriza a distribuição social dos custos e benefícios, ou seja, a eqüidade, coletivizando-se benefícios e custos. Assim, a mais alta qualidade seria aquela que produzisse a maior utilidade para toda a população, de forma que todos contribuiriam de modo equivalente à sua capacidade de pagar. Para Donabedian esta definição é tida como utópica, e é de responsabilidade das escolas descobrirem e ensinarem as estratégias de atenção, com maior possibilidade de alcançar este fim. Para que esta definição possa ser operacionalizada teria que desaparecer a "mão invisível" (do mercado regulador) e o Estado definir políticas de sáude ef etivas. Isto não significa necessariamente a estatização dos serviços de saúde. Em outros setores da economia, como transportes por exemplo, a regulação estatal funciona e é operada, na sua maioria, pelo setor privado.

Finalmente, Donabedian define qualidade como "uma característica que os cuidados médiocs devem possuir em graus variáveis"(7). A qualidade está assim relacionada ao "bom cuidado" sendo este definido como a "classe da medicina que praticam e ensinam os líderes reconhecidos da profissão médica em determinado período social e cultural..."(7).

Dessa forma, qualidade se torna algo que o proponente quer que seja, embora reflita valores sociais e metas do sistema de saúde do qual é parte. O modelo "donabediano" tem trazido grande contribuição a uma área de conhecimento tão pouco explorada aqui no Brasil, como a de avaliação qualitativa e faz parte dos estudos corporativos racionalizadores ${ }^{(6)}$ que enfoca a avaliação da qualidade sob três aspectos: o de estrutura, processo e resultado usando como métodos a auditoria médica, análise de custos (custobenefício, custo-efetividade, etc.), avaliação da eficácia e segurança da tecnologia médica, acrescentando a satisfação do usuário como um indicador que vai retro-alimentar o sistema, no sentido de detectar falhas que possam impedir a comercialização do serviço.

Existem outras definições de qualidade como as apresentadas por H. VUORI(14): a de Qualidade Lógica* - que se refere à eficiência com a qual a informação é usada na tomada de decisões, e a de Qualidade Ótima, onde o que é significativo é a otimização dos serviços de saúde, considerando os custos como parte da qualidade e os benefícios obtidos (14). O nível de qualidade ótima não é a maximização, mas a otimização. Ou seja, o nível qualitativo de cuidados deve ser mantido nos limites onde os benefícios são maiores do que os custos, e dentro desta área, o nível qualitativo ótimo fica no ponto onde a relação custobenefício alcança o seu máximo. Se é assim, não adianta acrescentar serviços e portanto aumentar custos, se o benefício chegou ao limite. Esta definição exige um preparo técnico acurado para saber quando se deve parar, o que, às vezes, dada as limitações da medicina científica e à variabilidade das reações dos pacientes, nem sempre é possível.

A definição de qualidade utilizada é aquela que a coloca como uma variável contínua e conseqüente do sistema de gestão adotado, considerando-se que não há um sistema único de idéias em relação à qualidade e a relatividade que envolve a sua definição. Para diagnosticar o estilo gerencial, utilizou-se a metodologia definida por $\operatorname{Likert}^{(9)}$, que vem sendo adotada internacionalmente pelas empresas e com boa aceitação.

\section{Compreendendo o Sistema 4T}

As organizações modernas têm evoluido na busca de soluções que aumentem a produtividade e a sua competitividade no mercado. Para tanto, recorrem a diferentes técnicas que venham substituir o modelo taylorista de produção. Isso vem ocorrendo tanto no setor secundário, como no setor terciário da economia. A partir da década de 50, Likert e colaboradores

A principio não são observadas diferenciações entre estas duas definições 
realizaram pesquisas objetivando testar a eficácia de sitemas gerenciais, partindo do estilo de gestão adotado pelos gerentes de empresas norte-maericanas e comprovou a maior eficácia do Sitema que denominou de $4 \mathrm{~T}$. A metodologia utilizada por Likert ${ }^{(9)}$ permite identificar, através da aplicação de questionários, e medir em que ponto da escala de $1 \mathrm{a} 4$ incide o sistema administrativo da empresa, além de incluir tendências temporais na análise e através desse acompanhemento, constatar-se a eficácia ou não do sistema adotado. (Anexo 1)

A s organizações dos sistemas 1 e $2 \mathrm{~T}$ tendem para a inflexibilidade, têm dificuldades de adaptação às mudanças tecnológicas, de produtos, mercados e processo. Essas organizações são mais propensas a sair do mercado quando necessitam introduzir mudanças. As organizações que operam no sitema $4 \mathrm{~T}$ tendem a ser mais flexíveis, existindo melhor cooperação interdepartamental, pois a comunicação flui em todas as direções e é mais satisfatória; ocorrem importantes melhorias nas medições de produtividade e do rendimento, melhora a satisfação do empregado e estes são capazes de influenciar os superiores, sentindo-se responsáveis e motivados, eleva-se o espírito de equipe, enfim possui todas as características favoráveis à Gestão da Qualidade. Porém, apesar da eficácia do sistem 4T, Likert afirma que a maioria das organizações do mundo opera sobre os sistemas 1, 2 e 3T.

Likert parte do princípio que a percepção é a chave do comportamento. O comportamento de liderança dos subordinados tende a refletir o do superior; desta forma, este dissemina e se amplia nos sucessivos níveis hierárquicos da organização. Para tanto, ele se refere às pesquisas do Instituto de Pesquisa Social da Universidade de Michigan, que revelaram ser o clima organizacional* experimentado por um certo grupo de trabaho ou por um nível hierárquico específico, em uma organização, determinado pelo comportamento de escalões superiores, exceto para situações onde o alto escalão está separado dos demais por distância geográfica. Afirma ainda que, à medida que se desce na hierarquia, observa-se que os chefes são sempre mais influenciados pelo clima organizacional onde estão inseridos, exercendo porém uma influência sempre menor sobre os subordinados. Assim, o clima organizacional traz restrições ao tipo de administração que cada chefe gostaria de adotar e, à medi- da que se desce na hierarquia das organizações, é maior a pressão do clima organizacional sobre as chefias. Cabe concluir que, em uma organização do sistema 1 ou $2 \mathrm{~T}$, o chefe precisa ser muito corajoso para se desviar do padrão estabelecido. O mesmo ocorre no sistema 3T, porém aí a pressão é menor, tornando-se mais fácil para um chefe mudar para o sistema 4T.

Geralmente, as chefias dos serviços de enfermagem estão mais próximas do escalão operacional e portanto, na dependência do estilo gerencial utilizado pela organização. No sistema $4 \mathrm{~T}$ o ef eito do clima organizacional é benéfico, pois encoraja os escalões mais baixos a usarem os estilos de liderança e administração de conflito utilizados neste sistema, conferindo à chefia imediata uma capacidade maior de influenciar o primeiro escalão com êxito.

Vale ressaltar que distorções de percepção podem existir numa organização, resultando na tentativa frustrante de imprimir um estilo gerencial que de nada valerá, se se apresentar destorcido para os empregados. Baseado nisso, Likert defende que o princípio de liderança fundamental é o de relacionamentos de apoio, que só se aplica quando as pessoas com quem o líder trata, vêem o comportamento deste como favorável a seu sentido de valor pessoal( ${ }^{(9)}$. Ou seja. não basta o líder acreditar que está agindo dessa forma, é preciso que as pessoas com quem ele interage percebam assim.

No sistema 4T, um dos mecanismos de motivação não econômica, característica dos Sitemas 1, 2 e 3 , envolve compra do tempo de uma pessoa e, que isso, confere o direito de emitir ordens e exigir o seu cumprimento e se contitui uma forma de poder sobre os outros, estimulando o uso da insatisfatória e ineficiente "técnica ganhar-perder" na solução de conflitos. Esta técnica é inerente aos sitemas 1, 2, e de certa forma, ao sistema 3T, e é usada pela maioria das organinzações do mundo.

O sistema 4T confia na solução de conflitos através dos eficientes grupos de trabalho face a face, utilizando uma rede de interação-influência, pois a resolução de conflitos, quase sempre, envolve mudanças. Experimento conduzido por Lewin apud LIKERT (9) descobriu "que um método de decisão grupal, em que o grupo como um todo tomava a

Clima organizacional é definido como o ef eito do impacto do comportamento de liderança, por parte da cúpula e dos niveis mais altos de uma organização, sobre todos os niveis dessa mesma organização 
decisão de que seus membros deveriam mudar de conduta, era de duas a três vezes mais eficiente na produção de mudanças reais, do que um sermão exortando a mudança". Na visão do gerenciamento orientado para obtenção da qualidade total, as iniciativas de mudanças devem partir do primeiro escalão, atingindo os demais grupos como um ef eito em casca$\mathrm{ta}^{(5)}$.

Aqui é preciso destacar, como também o faz Likert, a necessidade de observar o sistema administrativo do ambiente externo que exerce inflluência recíproca nas organizações. "Até mesmo uma organização do sistema 4T, em um ambiente cujas organizações e instituições sejam predominantemente do sistema 1 ou $2 \mathrm{~T}$, experimentará uma série de pressões para mudar em direção a um sistema de administração com características semelhantes às que vigoram no ambiente externo".(9:61) Da mesma forma, ocorre com pessoas provenientes de um contexto dos sistemas 1 e $2 \mathrm{~T}$, que tenderão a repetir o comportamento compatível com estes sistemas. Na área de saúde é comum as pessoas manterem vínculos empregatícios com diferentes organizações. Na amostra estudada isso também se verifica, sendo que do total de profissionais, $53,4 \%$ trabalha em outro local. Para o grupo de enfermagem este percentual foi de $51,6 \%$.

Em relação ao ambiente externo, verifica-se que o hospital em estudo presta serviços a difcrentes empresas (seguros saúde, administradoras de planos de saúde, estatais), sindicatos, instituições religiosas, militares, enfim há uma pluralidade de organizações que podem influenciá-lo. A fonte de receita do hospital é predominantemente oriunda de empresas, havendo assim, uma relação de dependência recíproca. o que facilita as mútuas influências. Isto pode ser detectadod nas entrevistas quando foi colocado que "o hospital não dispõe de enfermaria específica parea doenças infecciosas porque os seguros e planos de saúde não cobrem este tipo de tratamento". Isto ć uma definição externa que interfere na estrutura organizacional. Outra, refere-se às solicitações de autorização e justificativas para a realização de procedimentos. implicando no aumento do volume do trabalho médico e resultando na inacabada tarefa de preencher estes relatórios médicos, causando reclamações destes profissionais que interpretam isto como "excessso de burocracia por parte das empresas e uma espécie de interferência na autonomia do trabalho médico", ou digamos, a manutenção de uma autonomia regulada. Estas cmpresas atuam sob uma racionalidade centrada no mercado, que se sustenta na econmia capitalista, cuja lógica é, às vezes, incompatível com os princípios assistenciais humanitários defendidos pelo hospital e sintetizado no slogan: "Ide, ensinai e curai".

Observa-se que o hospital também exerce certa influência sobre as empresas contratadas e conveniadas, tendo conseguido negociar com as mesmas, um contrato padrão e tabela de procedimentos (pacotes). A margem de manobra conseguida pelo hospital pode ser expressa nas suas características, sintetizdas em entrevista com assessoria do setor de credenciamento: "Este é hoje o maior hospital privado da Bahia com atendiomento ambulatorial (atende cerca de 1000 pacientes/dia), sem contar com a capacidade do laboratório, recursos de bio-imagem, além de um corpo médico super-especializado, qualificado. Então, não ter contrato com um hospital deste significa abrir mão de tudo isso, de qualidade, de tecnologia que só tem aqui".

Em outra entrevista com informante proveniente de uma das empresas, isso também é observado: "Este hospital tem credibilidade no mercado, tem tecnologia de ponta, sua conta é totalmente informatizada. Então as empresas pensam duas vezes antes de criar um atrito com este hospital, primeiro porque atende muitos pacientes e depois, tem-se cinco dias para conferir as contas, de modo que, se há dúvidas, você liga para o hospital e a velocidade de inf ormação é maior. Isto é feito só se for uma coisa que realmente justifique".

Complementa dizendo: "Eu vejo as ambulâncias de outros grandes hospitais aqui na porta deste hospital, eles vêm buscar aqui a tecnologia de ponta". Verifica-se assim que a tecnologia de ponta é um valor reconhecido pela clientela e que diferencia o hospital, tornando-o um pólo difusor de tecnologia na área de saúde. Tradicionalmente, esse tem sido o aspecto privilegiado nas avaliações da qualidade de serviços de saúde no Brasil. (10)

\section{ASPECTOS METODOLÓGICOS}

O estudo foi realizado no Hospital São Rafael (HSR) que é um hospital geral. privado, sem fins lucrativos, de alta tecnologia, situado no bairro de Pau da Lima, em Salvador-BA, e que mantém convênio com o sistema Único de Saúde, servindo de hospital de referência do Distrito Sanitário de que faz parte. Possui uma capacidade instalada de 442 leitos (sendo que estão ativados 242 leitos e na unidade de urgência/emergência são 17 leitos), mais de 200 convênios e contratos de assistência médica supletiva. É 
uma organização que tem um padrão distinto no que se refere a forma de organização do trabalho médico. É de corpo clínico fechado e sua estrutura organizacional foi montada com bases em princípios assistenciais, de ensino e pesquisa.

O estudo de caso foi realizado em duas etapas. A primeira fase objetivou identificar na "cultura organizacional", através da fala dos autores, símbolos e estruturas, a expressão dos princípios de qualidade do serviço e estabelecer relação entre essa "cultura"e fatores externos à organização (definições contidas em convênios e contratos). Foram realizadas 11 entrevistas com representantes das diretorias (executiva, médica, administrativa), assessores, gerente de organização, consultor de contratos e convênios e representantes das estruturas formais de controle de qualidade existentes $(\mathrm{CCIH}$, Comissão de Ética e Contas Médicas), assim como com os coordenadores de enfermagem e da área médica. Foram também realizadas observação focal e análises de documentos, normas, etc... participação em curso de "Qualidade no Atendimento" e reuniões de trabalho.

$\mathrm{Na}$ segunda fase, o objetivo foi detectar como funciona, na prática, o repasse dos princípios de qualidade para os empregados, como eles percebem e experienciam o estilo gerencial no cotidiano da Unidade de urgência/emergência e como operacionalizam a definição de qualidade proposta pela organização.

A coleta de dados teve a duração de cinco meses (maio a agosto/93), sendo que as observações e questionários foram aplicados na unidade de urgência / emergência por ser esta um local onde existem "protocolos" de atendimento formalizados, por se constituir em importante "porta de entrada" do hospital e realizar, ao mesmo tempo, procedimentos ambulatoriais e de internação. O questionário (anexo I) foi o mesmo utilizado por LIKERT e colab. ${ }^{(9)}$ Inclui variáveis que permitem estabelecer as características operacionais da organização (liderança, motivação, comunicação, interação, tomada de decisões, objetivos e controle), sendo acrescentadas variáveis referentes à qualidade tais como: organização do trabalho, ou seja, a forma como são sitematizadas e operacionalizadas as tarefas; participação, que se refere ao envolvimento dos empregados nas definições relativas ao trabalho e, estrutura aqui entendida como o conjunto de instrumentos físicos e jurídico-institucionais que podem interferir na qualidade.

A cada questão foi conferido 1, 2, 3 ou 4 pontos, de acordo com a localização da resposta (sistema 1, 2, 3 ou 4), obtendo-se, posteriomente, as médias anitméticas para cada questão, as quais foram utilizadas na análise.

As questões 1, 2, 3, 4, 5, 6, 22 a 29, 31 a 33 referem-se ao estilo gerencial e estão relacionadas às variáveis liderança, motivação, decisão e participação, objetivos e controle. As questões 7 a 10, referemse à administração da informação, estando realcionadas à variável comunicação. A questão 30 , embora pertença à variável objetivos, está relacionada à administração de "marketing", da mesma forma que as questões de 17 a 21 .

A análise estatística dos dados foi realizada mediante aplicação de teste estatístico não paramétrico "prova U de Mann-Withney"(12). Para as questões $26,29,33$ a 37 , usou-se a prova do "qui-quadrado"porque, para estas questòes, o nível de mensuração foi de uma escala nominal, enquanto que para as demais foi de uma escala ordinal. Foi considerado $\alpha=0,05$, destacando-se para análise, as questões cujo valor de " $p$ " foi menor que o $\alpha$ estabelecido. Para fins de análise do questionário, utilizou-se dois planos: grupo de enfermagem $\mathrm{x}$ grupo das demais categorias e grupo de enfermagem $x$ grupo gerencial.

A amostra estudada foi composta de 84 indivíduos, sendo que $95,2 \%$ correspondeu aos empregados do Pronto Atendimento e 4,8\% ao grupo dos gestores. Do total de empregados do PA (80 indivíduos), 49,4\% eram do sexo masculino e 50,6 do sexo feminino. Na distribuição por grupo, a enfermagem representou $42,5 \%$ e o grupo dos demais profissionais representou $57,5 \%$ sendo que destes $12,5 \%$ são da recepção, $40 \%$ médicos e $5 \%$ técnicos de radiologia. No grupo de enfermagem, os enfermeiros representaram $20,6 \%$ da amostra, os téncnicos $5,9 \%$ e os auxiliares $73,5 \%$.

\section{RESULTADOS}

De acordo com os dados apresentados no gráfico 1, não há homogeneidade na média das respostas referentes às variáveis estudadas. Em relação ao total das respostas, observa-se que há uma concentração da média entre os sitemas 2 e 3 com uma predominância do sistema 3 e relação ao 2 . Isto está de acordo com o descrito por LIKERT, quando af irma que a maioria das organizações do mundo está nos sistemas 2 e $3^{(9)}$. Ao se analisar a média das respostas para todos os profissionais (Gráfico 1), apenas a questão 25 se distanciou dos sistemas encontrados. Esta questão se refere a como se estabelecem os objetivos organizacionais, obtendo-se a média das respostas no sistema 1 (emitem-se ordens) 
Gráfico 1 - Médias das respostas por questão para todas as categorias

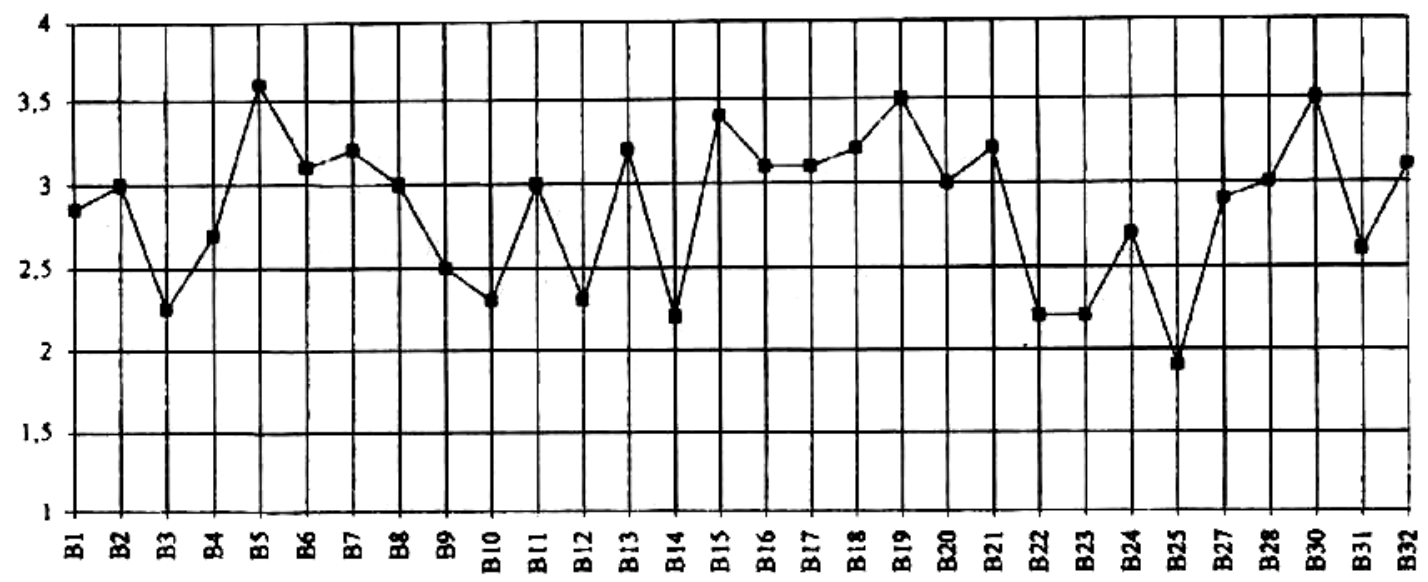

Gráfico 2 - Médias das respostas por questão para o grupo de enfermagem

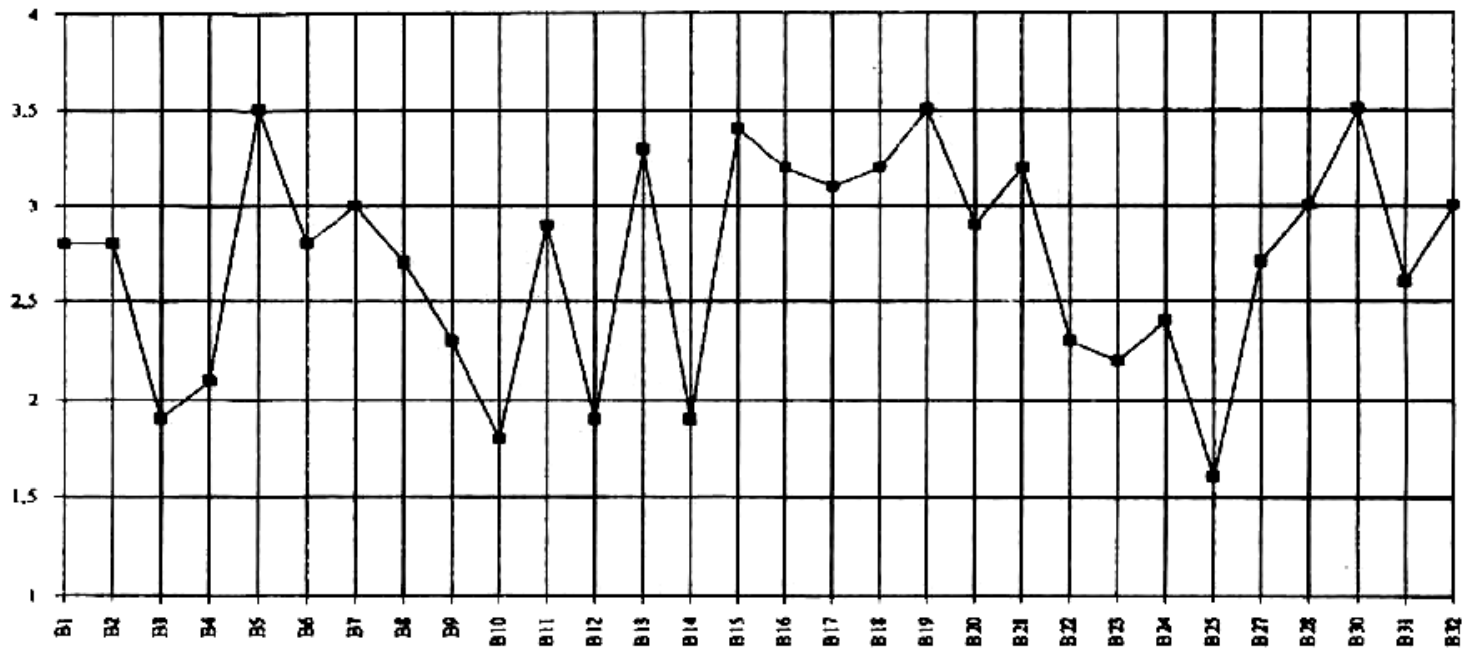

Gráfico 3 - Médias das respostas por questão para as demais categorias

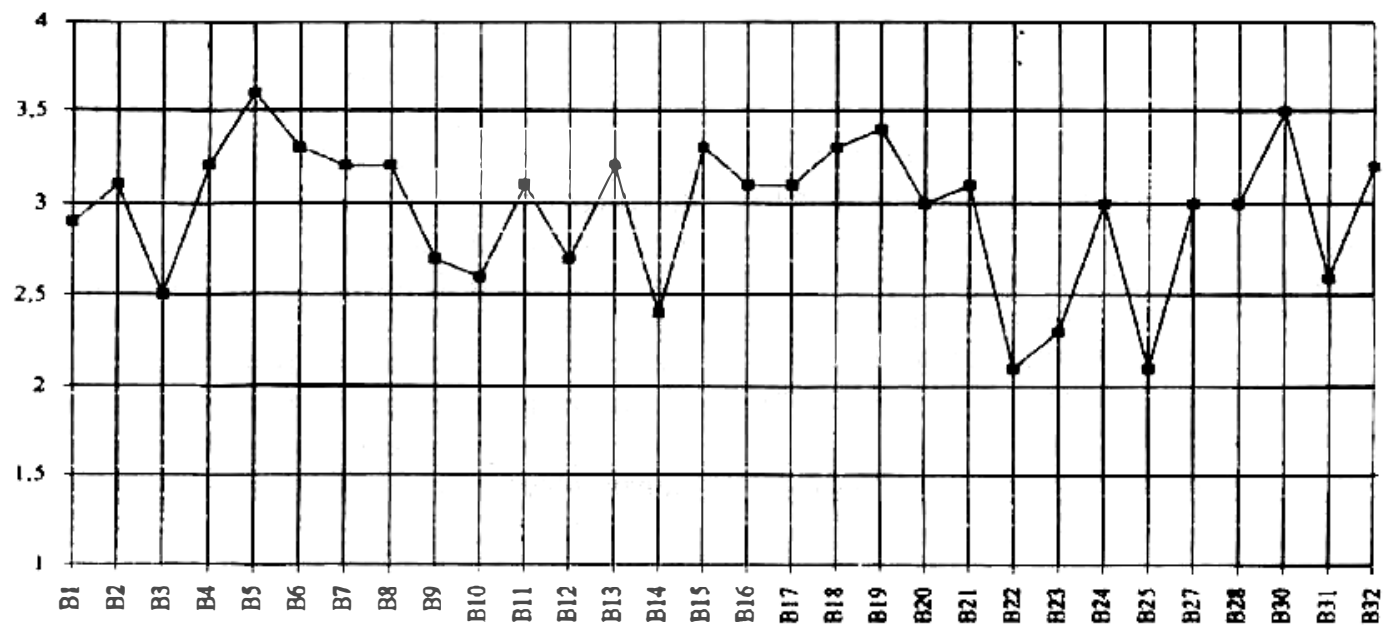

218 R. Bras. Enferm. Brasilia, v. 46, n. 3/4, 211-225, jul./dez. 1993 


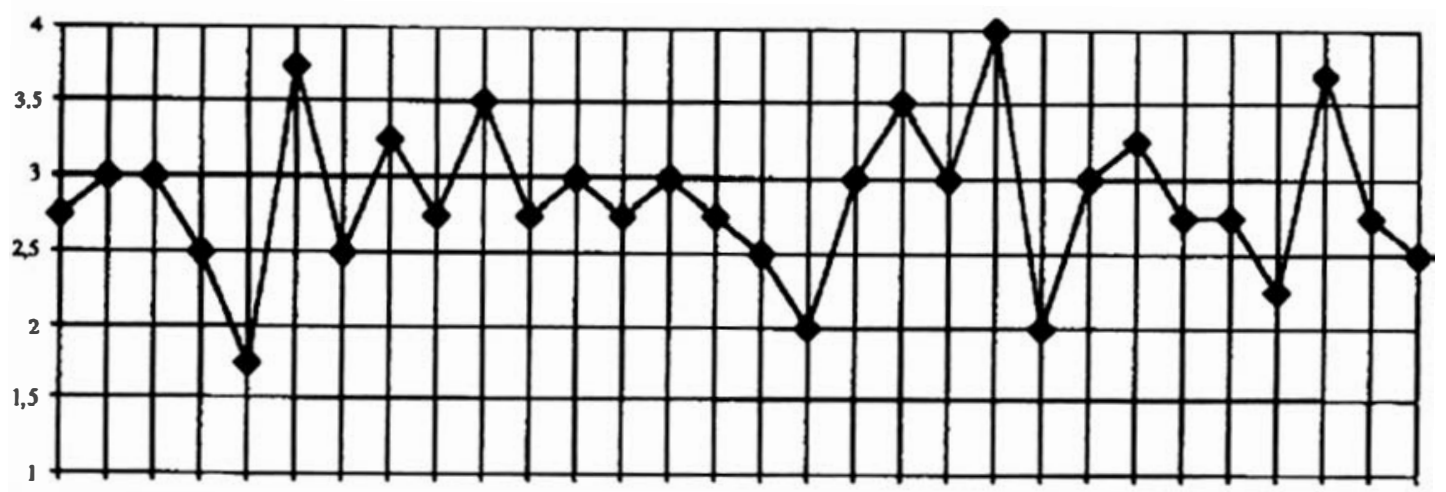

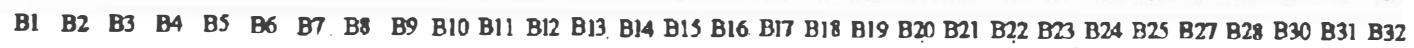

Quando se estuda o Grupo de Enfermagem (GE) separadamente, esta relação se inviverte (Gráfico 2). Ou seja, prevalece o sitema 2 sobre o 3 com r espectivamente $43,3 \%$ e $40 \%$. Este gnupo apresenta ainda $16,7 \%$ das questões com médias situadas no sistema 1. Dentre as questões com médias no sistema 1, estão a B3 (referente à variável liderança), 10 (comunicação), 12 e 14 (ref erem-se à organização do trabalho) e 25 (corresponde a objetivos organizacionais).

Ao se analisar a média das respostas por questão para o Grupo das Demais Categorias (GDC), observa-se que $66,66 \%$ das questões estão situadas no sitema 3 e 33,33\% no sistema 2. (Gráfico 3). Isto demonstra que para este grupo predomina o sistema $3 \mathrm{~T}$ sobre o $2 \mathrm{~T}$.

Quando se parte para a análise da média das rispostas apresentadas pelo Grupo Gerencial (GG), obıéın-se que em 3,33\% das questões situam-se no sistcma $1,50,0 \%$ no sistema $2,43,33 \%$ sitema 3 e $3.33 \%$ no sitema 4 . Ou seja, conforme percepção dos gestores. predominao sistema 2, seguido do sistema 3 (Grafico 4)

Estes dados pernitem concluir que não há uniformidade de percepção entre os grupos quanto ao estilo gerencial.

De acordo comos dados apresentados no Quadro 1, quando se relaciona o Grupo de Engermagem com o Grupo das Demais Categorias, do total das questões que apresentaram valor de " $p$ " menor que 0,004 . as que se referem ao estilo gerencial correspondem a $63,6 \%$, a administração da produção equivale a $18,2 \%$ e administração da informação corresponde a $18,2 \%$. Esses dados demonstram haver maior dif erenciação de percepção do grupo de enfermagem com relação a aspectos referentes ao estilo gerencial e, de certa forma, explicam o percentual das médias de respostas deste gnupo no sistema 1 de LIKERT.

Relacionando-se o Grupo de Enfermagem com o Grupo Gerencial, observa-se que do total de questões que apresentaram valor de " $p$ " menor que 0,05 , $42,8 \%$ correspondem ao estilo gerencial, $42,8 \%$ a administração da produção e $14,4 \%$ a administração da informação (Quadro 2).

Análise das questões cujas médias apresentaram significância estatística (valor de "p" menor que 0,05) entre os grupos: Grupos de Enfermagem (GE), Grupo das Demais Categorias (GDC) e Grupo Gerencial (GG).

Das questões referentes ao estilo gerencial, a B3 (procura-se saber as idéias dos subordinados e usá-las se valerem a pena?) o GE obtém média de respostas no sistema 1 (raramente) e o GDC no sistema 2 (às vezes). A média de respostas dos técnicos e auxiliares de enfermagem foi no sistema 2 (às vezes) e para os enfermeiros, a média se localizou no sistema 1 (raramente). A esta mesma questão o GG responde no sistema 3 (freqüentemente). Cabe indagar o por quê das diferentes percepções entre os dois primeiros grupos, já que ambos estão sujeitos à mesma gestão? Segundo LIKERT, de nada adianta o líder ter um comportamento de apoio, se os subordinados não percebem assim ${ }^{(9)}$. Estaria havendo uma distorção de percepção, ou haveria algum fator intrínseco ao primeiro grupo, que o levou a responder de acordo com condicionantes extra-organizacionais. Prevalecendo a segunda afirmativa, pode-se inf erir que as respostas devem ser buscadas na história da enfermagem.

As questões $\mathrm{B} 4$ e $\mathrm{B} 6$, referem-se à variável motivação. Para B4 (Usa-se predominantemente medo, ameaças, castigo, recompensas, participação?) tanto o GE como o GDC respondeu no sistema 2 (recom- 
Quadro 1 - Relação de Questões que apresentaram significância estatística* enter o Grupo de Enfermagem x Grupo das Demais Categorias.

\begin{tabular}{|c|c|c|c|c|}
\hline Questão/ Dimensão & Descrição & $\begin{array}{l}\text { Resposta para } \\
\text { Grupo de } \\
\text { Enfermagem } \\
\end{array}$ & $\begin{array}{l}\text { Respostas para o } \\
\text { Grupo demais } \\
\text { Categorias }\end{array}$ & Valor de $p$ \\
\hline B3 Estilo Gerencial & $\begin{array}{l}\text { Procura-se saber as idéias dos } \\
\text { subordinados e usá-la se valerem à } \\
\text { pena }\end{array}$ & Raramente & Às vezes & 0,0053 \\
\hline B4 Estilo Gerencial & $\begin{array}{l}\text { Usa-se predominantemente (a) medo, } \\
\begin{array}{lll}\text { (b) ameaças, } & \text { (c) castigo, (d) } \\
\text { recompensas e (e) participaça. }\end{array}\end{array}$ & $\begin{array}{l}\text { Recompensas e } \\
\text { algumas vezes } \\
\text { castigo }\end{array}$ & $\begin{array}{l}\text { Recompensas e } \\
\text { algumas vezes } \\
\text { castigo }\end{array}$ & 0,0003 \\
\hline B6 Estilo Gerencial & $\begin{array}{l}\text { Os programas de ensino e pesquisa } \\
\text { desta organizaçăo funcionam como } \\
\text { atrativos? }\end{array}$ & Não sabe & Parcialmente & 0,0296 \\
\hline $\begin{array}{l}\text { B8 Adm. da } \\
\text { Informaçăo }\end{array}$ & $\begin{array}{l}\text { Qual a precisão da comunicação para } \\
\text { baixo? }\end{array}$ & \begin{tabular}{|l} 
Com censura pelos \\
subordinados
\end{tabular} & Precisăo limitada & 0,0019 \\
\hline $\begin{array}{l}\text { B10 Adm. da } \\
\text { Informação }\end{array}$ & $\begin{array}{l}\text { Qual o seu conhecimento em relação à } \\
\text { pesquisa desta unidade sobre } \\
\text { qualidade do atendimento? }\end{array}$ & $\begin{array}{l}\text { Desconhece } \\
\text { totalmente }\end{array}$ & Ouviu falar & 0,0028 \\
\hline $\begin{array}{ll}\text { B12 } & \text { Adm. da } \\
\text { Produçăo }\end{array}$ & Como săo estabelecidos os padrões? & Emitem-se instruçס̃es & $\begin{array}{l}\text { Instruçōes e } \\
\text { solicita-se } \\
\text { alquma opinião } \\
\end{array}$ & 0,0025 \\
\hline $\begin{array}{l}\text { B14 Adm. da } \\
\text { Produçăo }\end{array}$ & Como săo estabelecidos os fluxos? & Emitem-se instruçס̃es & $\begin{array}{l}\text { Instruçőes e } \\
\text { solicita-se } \\
\text { alquma opiniåo }\end{array}$ & 0,0362 \\
\hline B24 Estilo Gerencial & $\begin{array}{l}\text { Qual a contribuição da tomada de } \\
\text { decisåo para a motivaçăo? }\end{array}$ & Relativamente pouca & Alguma contribuiçăo & 0,0136 \\
\hline B25 Estilo Gerencial & $\begin{array}{l}\text { Como se estabelecem os objetivos } \\
\text { organizacionais? }\end{array}$ & Emitem-se ordens & $\begin{array}{l}\text { Ordens e solicita-se } \\
\text { alguma opiniăo. }\end{array}$ & 0,0183 \\
\hline B27 Estilo Gerencial & $\begin{array}{l}\text { Os objetivos organizacionais são } \\
\text { compreendidos pelos empreqados? }\end{array}$ & Năo totalmente & Às vezes & 0,0255 \\
\hline B29 Estilo Gerencial & $\begin{array}{l}\text { A preocupaçăo com qualidade total faz } \\
\text { parte dos objetivos desta organizaçăo? }\end{array}$ & $\begin{array}{l}25,0 \%=\text { em parte } \\
75,0 \%=\text { sim }\end{array}$ & $\begin{array}{l}9,1=\text { não } \\
6,1=\text { não sabe } \\
36,4=\text { em parte } \\
48,5=\text { sim }\end{array}$ & 0,0278 \\
\hline
\end{tabular}

* Nível de significância de 5\%

pensas e algumas vezes castigo). Na questão B6 (Os programas de ensino e pesquisa desta organização funcionam como fatores atrativos?) o GE responde com média no sistema 2 e o GDC no sitema 3 (parcialmente). O fato do hospital possuir uma escola de formação de auxiliares de enfermagem pode ter influenciado na resposta desta categoria.

A questão B24 corresponde à variável decisão e participação, onde pergunta-se qual a contribuição do processo de tomada de decisão para a motivação, ao que o GE responde sistema 2 (relativamente pouca) e o GDC sitema 3 (alguma contribuição). Esta questão cstá relacionada com á B22 (a que nível são tomadas as decisões), em que os dois grupos respondem sitema 2 (estratégia no primeiro escalão e alguma delegação).
As questões B25, 27 e 29, referem-se aos objetivos organizacionais. A B25 trata da forma como são estabelecidos os objetivos organizacionais. Para o GE a média de respostas foi no sitema 1 (emitem-se ordens). Para o GDC e também para o GG a média incidiu no sistema 2 (ordens e solicita-se alguma opinião). A questão B27 (os objetivos organizacionais são compreendidos pelos empregados?) o $\mathrm{GE}$ responde no sitema 2 (não totalmente) e o GDC no sitema 3 (às vezes). A resposta dada pelo grupo de enfermagem a esta questão talvez possa estar relacionada com a questão B25. Pelo explicado por Likert, o fato do grupo perceber que os objetivo são estabelecidos através de ordens, dificulta o entendiemnto por estes empregados. Essa mesma questão, quando analisadas as categorias de enfermagem separadamente. encontra-se que enfermeiros e técnicos res- 
Quadro 2 - Relação de Questões que apresentaram significância estatística* entre o Grupo Gerencial e o Grupo de Enfermagem.

\begin{tabular}{|c|c|c|c|c|}
\hline Questão/ Dimensão & Descrição & $\begin{array}{l}\text { Respostas para } \\
\text { Grupo Gerencial }\end{array}$ & $\begin{array}{l}\text { Respostas para } \\
\text { Grupo de } \\
\text { Enfermagem } \\
\end{array}$ & Valor de $p$ \\
\hline B3 Estilo Gerencial & $\begin{array}{l}\text { Procura-se saber as idéias dos } \\
\text { subordinados e usá-la se valerem à } \\
\text { pena? }\end{array}$ & Frenquentemente & Raramente & 0,0476 \\
\hline B5 Estilo Gerencial & $\begin{array}{l}\text { Onde se sente responsabilidade pela } \\
\text { garantia da qualidade do servico? }\end{array}$ & Predominantemente & Nos empregados & 0,0014 \\
\hline $\begin{array}{l}\text { B10 Adm. da } \\
\text { Informaçăo }\end{array}$ & $\begin{array}{l}\text { Qual o seu conhecimento em relação à } \\
\text { pesquisa desta unidade sobre } \\
\text { "Qualidade do Atendimento"? }\end{array}$ & $\begin{array}{l}\text { Conhece } \\
\text { parcialmente }\end{array}$ & $\begin{array}{l}\text { Desconhece } \\
\text { totalmente }\end{array}$ & 0,0023 \\
\hline $\begin{array}{l}\text { B16 Adm. da } \\
\text { Produçăo }\end{array}$ & O seu trabalho é padronizável? & $\begin{array}{l}\text { Alguns poucos } \\
\text { procedimentos }\end{array}$ & $\begin{array}{l}\text { Grande parte dos } \\
\text { procedimentos }\end{array}$ & 0,0408 \\
\hline B25 Estilo Gerencial & $\begin{array}{l}\text { Como se estabelecem os objetivos } \\
\text { organizacionais? }\end{array}$ & $\begin{array}{l}\text { Ordens e solicita-se } \\
\text { alguma opiniâo }\end{array}$ & Emitem-se ordens & 0,0146 \\
\hline $\begin{array}{l}\text { B35 Adm. da } \\
\text { Produçăo }\end{array}$ & $\begin{array}{l}\text { As instalaçőes fisicas são adequadas } \\
\text { ao bom desenvolvimento do trabalho? }\end{array}$ & \begin{tabular}{|l|}
$25,0 \%=$ são \\
parcialmente \\
$75,0 \%=$ são totalmente
\end{tabular} & \begin{tabular}{|l}
$11,8 \%=$ năo \\
$2,9 \%=$ não sabe \\
$61,8 \%=$ săo \\
parcialmente \\
$23,5 \%=$ são totalmente
\end{tabular} & 0,0436 \\
\hline $\begin{array}{l}\text { B36 Adm. da } \\
\text { Produçăo }\end{array}$ & $\begin{array}{l}\text { Os RH são quantitativamente } \\
\text { suficientes? }\end{array}$ & \begin{tabular}{|l|}
$50,0 \%=$ são \\
parcialmente \\
$50,0 \%=$ são totalmente
\end{tabular} & $\begin{array}{l}44,1 \%=\text { não } \\
8,8 \%=\text { não sabe } \\
41,2 \%=\text { são } \\
\text { parcialmente } \\
5,9 \%=\text { são totalmente }\end{array}$ & 0,0212 \\
\hline
\end{tabular}

* Nível de significância de 5\%

pondem sistema 2 (não totalmente) e os auxiliares sistema 3 (às vezes). Observa-se aí uma independência de visão nas respostas obtidas na questão B27 entre enfermeiros e auxiliares. Isto reforça a idéia "likertiana" de que que, à medida que se desce na hierarquia, observa-se que os chefes exercem uma influência sempre menor sobre os subordinados, quando se compara à influência exercida pelo primeiro escalão.

Para a questão B29 o tratamento estatístico foi diferenciado das demais, ou seja, trabalhou-se com frequências e não com médias. Pergunta-se se a preocupação com qualidade faz parte dos objetivos da organização, ao que $75 \%$ do GE responde sim e $25 \%$ responde em parte. Já o GDC $48,5 \%$ responde sim, $36,4 \%$ em parte, $9,1 \%$ responde que não e $6.1 \%$ não sabe (Quadro I). O Grupo de Enfermagem demonstra perceber mais, que a preocupação com a qualidade faz parte dos objetivos organizacionais.

Das questões referentes à adminitração da informação, a B8 é referentes à variável comunicação (qual a precisão da comunicação para baixo), obtémse para o GE média no sitema 2 (com censura pelos subordinados) e para o GDC sistema 3 (precisão limitada). A outra questão que também é correlacio- nada à variável comunicação, trata do conhecimento dos grupos em relação à pesquisa realizada na unidade sobre qualidade do atendimento e o GE obtém média no sitema 1 (desconhece totalemnte), o GDC sitema 2 (ouviu falar) e o GG sitema 3 (conhece parcialmente). Isto parece indicar uma dificuldade em fazer com que algumas informações cheguem formalmente, aos níveis operacionais.

Relacionando-se o Grupo de Enfermagem com o Grupo Gerencial, ainda obtém-se questões onde se encontra valor de "p"menor que 0,05 , tais como as questões B5 correspondente à variável motivação. B 16 referente à organização da produção, B35 e B36 que correspondem à estrutura (Quadro 2). Para B5 (onde se sente responsabilidade pela Garantia da Qualidade ) o GG responde com média no sitema 1 (predominantemente no primeiro escalão) e o GE responde sistema 3 (nos empregados). Estas respostas confirmam a visão predominante nos serviços de saúde onde, prestadores se sentem responsáveis pela Garantia da Qualidade destes serviços. Para avançar em direção à Qualidade Total, esta responsabilidade deve ser compartilhada por todos os membros da organização, numa visão sistêmica de que o trabal ho de um é importante para o do outro e para o conjunto. 
As demais questões se referem à administração da produção. A B 16 (seu trabalho é padronizável?) o GG obtém média no sistema 2 (alguns poucos procedimentos) e o GE sistema 3 (grande parte dos procedimentos). Estes resultados refletem a natureza do trabalho de cada grupo.

As questões B35 e 36 correspondem à variável estrutura e foram analisadas mediante freqüências, revelando diferentes percepções. Para B35 (as instalações físicas são adequadas ao bom desenvolvimento do trabalho?), para $75 \%$ do GG são totalmente e para $25 \%$ são parcialmente. Já para o $\mathrm{GE}, 61,8 \%$ responde que são parcialmente, $23,5 \%$ são totalmente, $11,8 \%$ responde que não são e $2,9 \%$ não sabe. A unidade vivenciou uma problemática em relação à área física que, devido ao rápido aumento da demanda, necessitava de expansão, mas que já estava sendo realizada. Isto apareceu nas entrevistas com informantes das demais categorias, mas para a enfermagem não foi apontado como um problema que inteferisse no bom desempenho do trabalho.

Na questão B36 (os recursos humanos são quantitativamente suficientes?) para $50 \%$ do GG são totalmente, e para $50 \%$ são parcialmente. Para o GE, $44,1 \%$ responde que não, $41,2 \%$ são parcialmente, $5,9 \%$ totalmente e $8,8 \%$ responde que não sabe (Quadro 2). Geralmente quando a gestão é descentralizada, compondentes de ordem estrutural tendem a ser compatíveis entre o grupo gerencial e operacional.

Convém destacar a necessidade de se observar que os membros de uma organização possuem dois quadros de ref erência ao responderemalguns itens do questionário. Um, é o próprio gnupo imediato de trabalho do entrevistado e outro, é a organização total. Dessa forma, as respostas para a mesma questão podem ser bastante dif erentes em relação aos quadros de referência do respondente. Isto se verifica neste trabalho para algumas questões como: B3, B 10, B35 e 36 .

\section{CONCLUSÃO}

A discussão sobre qualidade chega aos serviços de saúde da mesma forma que chegou aos demais setores da economia, ou seja, atrelada à competitividade e à produtividade, face ao colapso das políticas públicas de financiamento do setor e ao crescimento da assistência médica supletiva. Os serviços de saúde vêm desenvolvendo, há bastante tempo, métodos de controle de qualidade, técnicas que estão incorpora- das às práticas dos profissionais da área e que não privilegiam o conceito de satisfação do consumidor, da forma como vem se defendendo na indústria e demais setores, onde as leis do mercado são soberanas. O fato de consumidores de serviços de saúde possuírem estoques de conhecimentos dif erentes daqueles dominados pelos técnicos é uma das limitações apontadas para que nas avaliações de qualidade destes serviços, seja privilegiado este componente.

A definição de qualidade expressa pelos profissionais de saúde atribui a si a responsabilidade de operacionalizar o sistema assistencial com qualidade, sendo tarefa da organização, assegurar meios para que isso se concretize. Observou-se que variáveis extra-organizacionais interferem, sendo a capacidade tecnológica da empresa fator importante na correlação de forças entre hospital e financiadores da assistência. A operacionalização do conceito de qualidade para o grupo de enfermagem se dá no território das definições que comportam valores profissionais e organizacionais, dentro de um conteúdo de modernização de base estrutural e tecnológica.

Não foi encontrado um sistema único de percepção quanto ao estilo gerencial, tendo variado entre os sistemas 2 e 3 de Likert, sendo que para o grupo de enf ermagem houve uma variação entre os sistemas 1 e 3, o que indica um maior distanciamento deste gnupo, quando comparado com o grupo das demais categorias, do sistema de Gestão orientado para o Controle da Qualidade por Toda a Empresa (CQTE).

Gerenciar Qualidade Total em serviços hospitalares implica reconhecer a complexificação crescente do hospital e sua burocratização, a incorporação de novas tecnologias (informática, tecnologias gerenciais, assistenciais), o surgimento de novas categorias profissionais que não cuidam propriamente do assistir, mas da produção intermediária, e a existência de conflitos decorrentes de tal forma de organizar e financiar a produção. Embora a definição de qualidade, na prática, esteja restrita aos mecanismos tradicionais de Garantia de Qualidade e centrada no grupo saúde, o processo de gestão voltado para a Qualidade Total passa por uma reorganização interna, que deve se centrar não mais em serviços ou departamentos, mas em sistemas integrados de produção, para que prevaleça a lógica ético, humanitária do assistir com qualidade, considerando-se a satisfação do usuário, mesmo numa socidedade centrada no mercado. 


\section{REFERÊNCIAS BIBLIOGRÁFICAS}

1. AZEVEDO, A.C. O futuro dos hospitais e a gestão da qualidade. Rev. Paulista de Hospitais. v.40, n.5, p.53-9, maidez/1992.

2. BRAGA NETO, Francisco Campos. Examinando Alternativas para a Administração dos Hospitais: Os Modelos de Gestão por Linhas de Produção. Rio de Janeiro: Escola Nacional de Saúde Pública/FIOCRUZ. 1991. Dissertacão de Mestrado.

3. BRASIL, Ministério da Saúde. Instrumento de avaliação para hospital geral de médio porte. Brasilia: Centro de Documentação do Ministério da Saúde, 1986. 75 p.

4. CAMPOS, V. F. Gerência da Qualidade Total: Estratégia para aumentar a competitividade da empresa brasileira. Belo Horizonte: Fundação Christiano Ottonni, Escola de Engenharia da UFMG, 1990. $187 \mathrm{p}$.

5. CERQUEIRA NETO, Edgard Pedreira de. Gestão da Qualidade - Principios e Métodos. $1^{2}$ ed. São Paulo: Pioneira, 1991. 156p.

6. DONABEDIAN, Avedis. Evaluating the quality of medical care. Milbank Memorial Fund Quarterly. v. 44, part 2, p. 166-203. July, 1966.

7. The definition of Quality and approaches to its assessment. Series: Explorations in quality assessment and monitoring. Vol I. Health Administration Press. Ann Arbor. Michigan, USA, 1980. 157p.
8. JOHNSON, A. C. \& SHULZ, R. Administração de Hos pitais Tradução de Carlos José Malferrari, Lourdes Torres de Cerqueira, Haino Burmester et alli. São Paulo: Pioneira, 1979, pg. 105-25.

9. LIKERT, Rensis \& LIKERT, Jane Gibson. Administração de Conflitos: Novas Abordagens Tradução de Joaquim O. P. da Silva. São Paulo: McGraw-Hill, 1979. 393 p.

10. PEIXOTO, Marisa Ribeiro Bastos. Tecnologia no setor de saúde: critérios de avaliação de qualidade dos serviços hospitalares. Belo Horizonte: Faculdade de Ciências Econômicas / UFMG. 1990. Dissertação de Mestrado. 248p.

11. OFFE, Claus. Problemas Estruturais do Estado Capitalista. São Paulo: McGraw-Hill, 1979, 350p.

12. SIEGEL, Sidney. Estatistica Não-paramétrica (para as ciências do comportamento). São Paulo: McGraw-Hill, 1979. $350 \mathrm{p}$.

13. TREVIZAN, Maria Auxiliadora. Enfermagem Hospitalar: Administração \& Burocracia. Brasilia: Universidade de Brasilia, 1988. 142p.

14. VUORI, H. A qualidade da Saúde. Divulgação em Saúde para Debate. CEBES: Londrina. n. 1, fev. 1991. p. 17-25.

15. Quality assurance of health services. Copenhagen: WHO Public. Health in Europe, n. 16, 1982. 126p.

Recebido para publicação em 4/12/93. 

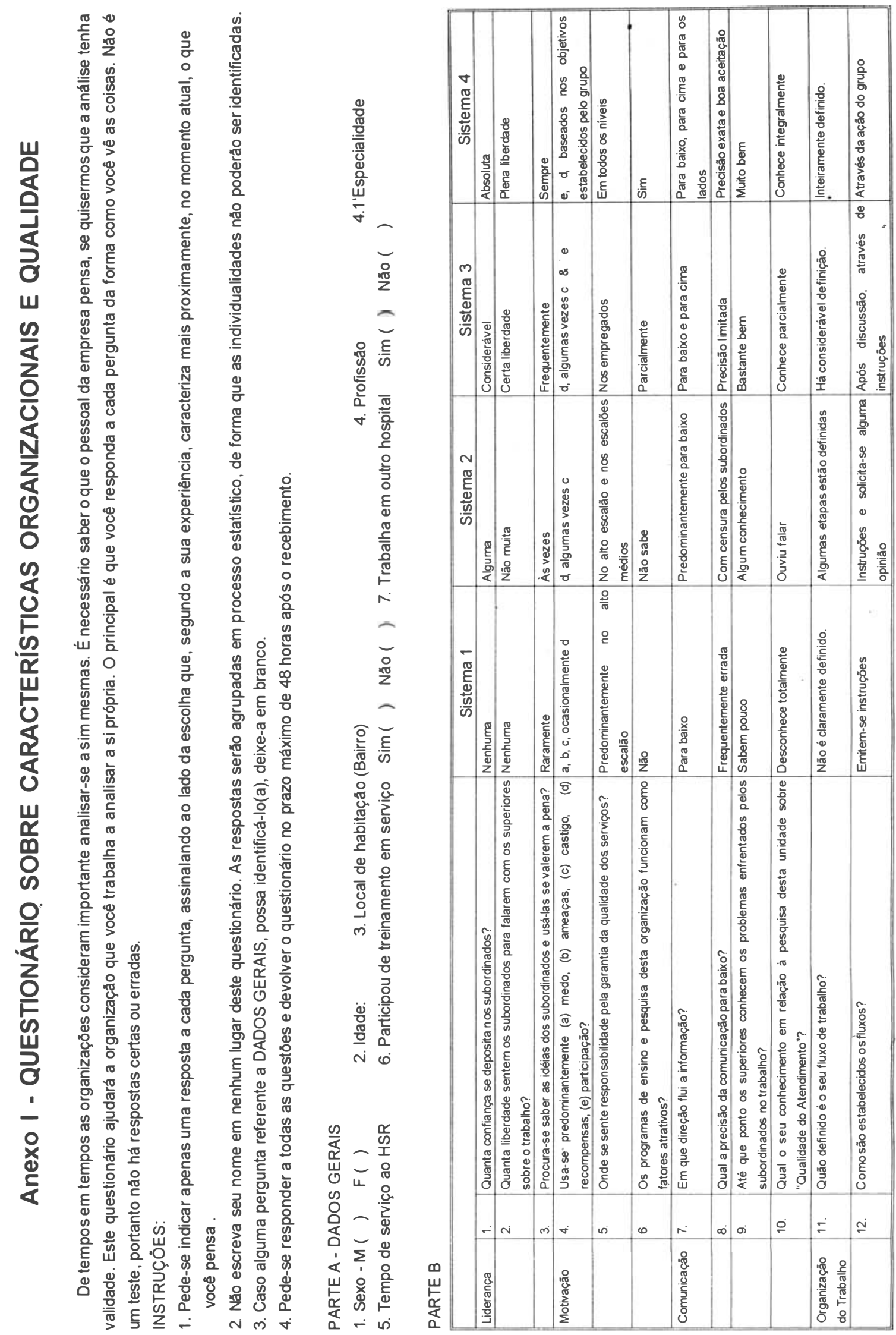

224 R. Bras. Enferm. Brasília, v. 46, n. 3/4, 211-225-, jul./dez. 1993 


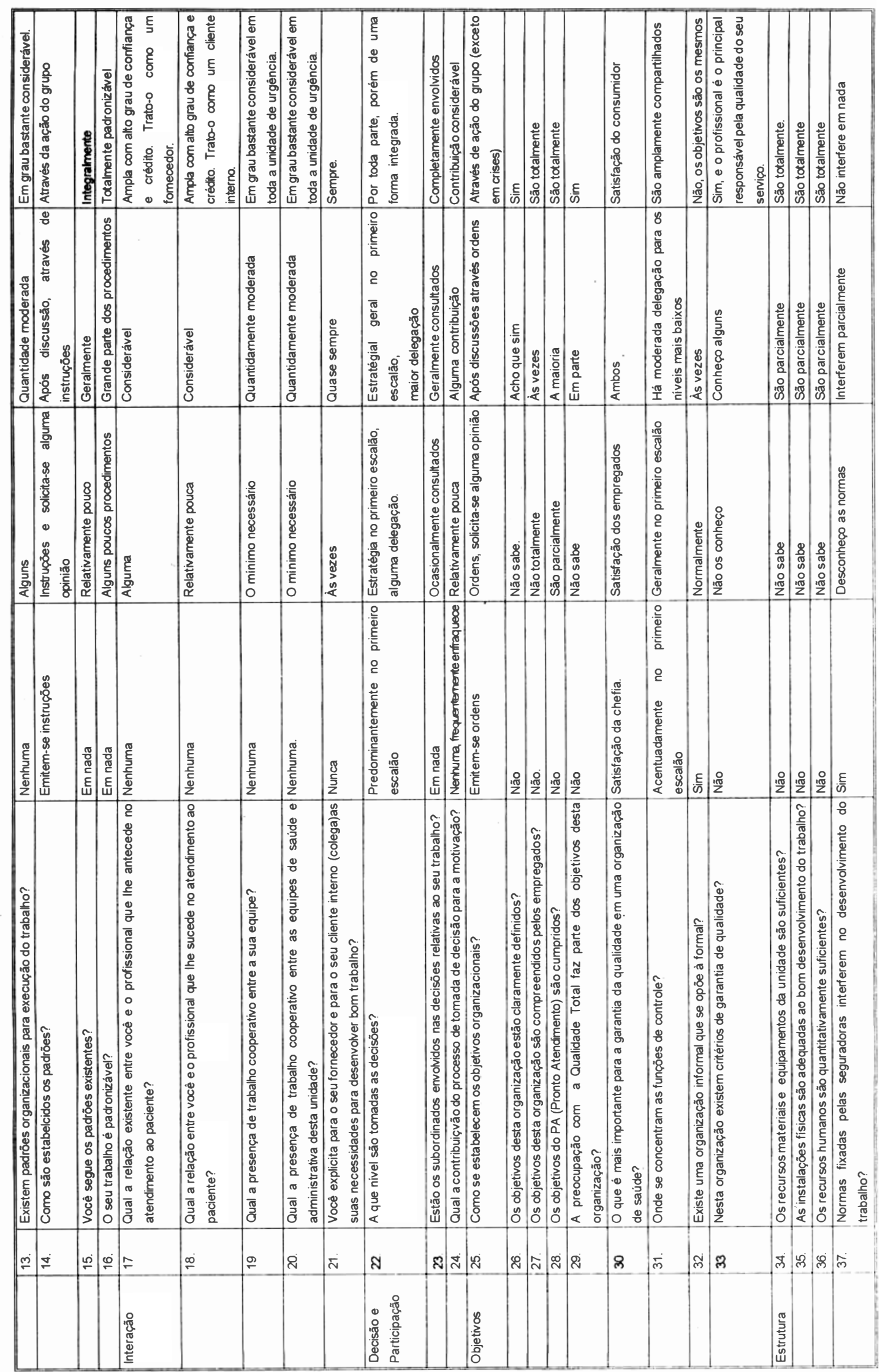

